\section{IN VITRO ACTIVITY OF ARBEKACIN AGAINST CLINICAL ISOLATES OF METHICILLIN-RESISTANT Staphylococcus aureus IN A HOSPITAL}

\section{Yoshiyuki KawaKami, Chizumi Furuwatari, Takayuki Akahane, Yukie Okimura, Ken'ichi Furihata ${ }^{\dagger}$, Tsutomu Katsuyama ${ }^{\dagger}$, and Hideki Matsumoto ${ }^{\dagger \dagger}$ \\ Central Clinical Laboratories, Shinshu University Hospital, \\ ${ }^{\dagger}$ Department of Laboratory Medicine, \\ ${ }^{\dagger \dagger}$ Department of Bacteriology, \\ Shinshu University School of Medicine, Matsumoto, 390, Japan}

(Received for publication October 15, 1993)

The frequency of isolation of methicillin-resistant Staphylococcus aureus (MRSA) strains from patients and hospital environments has becoming higher and higher in recent years ${ }^{1,2)}$. MRSA is now one of the most important pathogens of the nosocomial infections in Japan ${ }^{3,4)}$. No doubt, this is ascribed to the very low susceptibility of MRSA strains to various chemotherapeutic agents ${ }^{3 \sim 6)}$. Arbekacin (ABK) [1-N-(S)-4 amino-2-hydroxybutyryl-3',4'dideoxykanamycin B], a semisynthetic aminoglycosidic antibiotic has recently become into clinical use, and its efficacy has been reported ${ }^{7 \sim 9}$.

This led us to re-evaluate the in vitro activity of the ABK against MRSA isolates together with other chemotherapeutic agents in current use for comparison, as the $\mathrm{ABK}$ is now considered to be one of the few drugs effective for the treatment of patients with MRSA infection.

\section{MRSA Strains Examined}

A total of 496 MRSA strains, isolated during the years 1989 to 1992 from clinical specimens submitted to our laboratory, was used in this study. They were comprised of 82 strains from pharyngeal swab, 84 from urine, 185 from pus, 90 from nose, 25 from sputum, and 30 from miscellaneous materials which included the 16 from blood specimens. Only one strain from each patient was served for the examination. These strains were identified as $S$. aureus with the Vitek GPI Cards (Vitek Systems, BioMerieux Vitek, Inc., Hazelwood, Mo., U.S.A.) and/or ID-Test SP-18 System (Nissui Pharmaceuticals Co., Ltd., Tokyo, Japan).

\section{Susceptibility Tests}

This was carried out by the method as recommended by Japanese Association of Chemotherapy (Chemotherapy, 29: 76 77, 1981). The minimal inhibitory concentration (MIC, defined here as the lowest concentration of an agent that inhibited visible growth at the cultural condition given below) was determined against the following ten chemotherapeutic agents, i.e., arbekacin, gentamicin (GM), amikacin (AMK), fosfomycin (FOM), chloramphenicol, minocycline, imipenem (IPM), methicillin (DMPPC), vancomycin (VCM), and ofloxacin. In a few instances, resistances to clindamycin, ribostamycin (RSM), lividomycin (LVD), butyrocin (BUTY), neomycin (NM), tobramycin (TOB), sisomicin (SISO), astromycin (ASTM), netilmicin (NTL), micronomicin (MCR), kanamycin (KM), dideoxykanamycin B (DKB), and isepamicin (ISP) were also tested. The medium used was the cationsupplemented Mueller-Hinton agar (MMH; Eiken Chemical Co., LTD., Tokyo, Japan). For FOM, glucose-6-phosphate was added to the medium at the concentration of $25 \mu \mathrm{g} / \mathrm{ml}$, and as for IPM, $2 \%$ sodium chloride was incorporated into the medium, respectively, as recommended by THORNSBERRY et $a l .{ }^{10,11)}$. Saline cell suspension for the inoculation was prepared from the growth on Heart Infusion (HI) agar (Eiken Chemical Co., Ltd., Tokyo, Japan) incubated at $35^{\circ} \mathrm{C}$ overnight. Turbidity of the suspension was adjusted to $0.5 \mathrm{McF}$ arland standard. A loopful of the suspension $(15 \mu l)$ was streaked on the agar plates. The results were read after incubation at $35^{\circ} \mathrm{C}$ for 48 hours.

\section{Resistance of the MRSA Strains}

Results of the tests are summarized in Table 1. Presented in the Table were the MICs that inhibited the growth of the $50 \%$ (MIC50) and 90\% (MIC90) strains from each of the sources. No MRSA strain was inhibited its growth by DMPPC at the concentration of lower than $12.5 \mu \mathrm{g} / \mathrm{ml}$ and MIC 90 of this drug against the strains tested were higher than $800 \mu \mathrm{g} / \mathrm{ml}$. Both ABK and VCM were more active than any other drugs examined. Two strains were demonstrated to be resistant to ABK. The MICs of the resistant strains were $12.5 \mu \mathrm{g} / \mathrm{ml}$ and $25 \mu \mathrm{g} / \mathrm{ml}$, respectively. The former was isolated from pus of otitis media and the latter came from urine of a patient with urinary tract infection. The two strains were also resistant to KM, DK B, AMK, TOB, GM, SISO, NTL, MCR, ISP, NM, RSM, LVM, BUTY, ASTM but sensitive to streptomycin. This result 
Table 1. Susceptibility of 496 MRSA strains against 10 chemotherapeutic agents

\begin{tabular}{|c|c|c|c|c|c|c|c|c|}
\hline \multirow[t]{2}{*}{ Drug } & \multirow{2}{*}{\multicolumn{2}{|c|}{$\begin{array}{c}\text { MIC range } \\
(\mu \mathrm{g} / \mathrm{ml}) \quad(\mu \mathrm{g} / \mathrm{ml}) \\
\text { Among a total of } \\
496 \text { strains }\end{array}$}} & \multicolumn{2}{|c|}{$\begin{array}{l}\text { MIC ( } \mu \mathrm{g} / \mathrm{ml}) \text { required to inhibit } \\
\text { following (\%) of } 82 \text { isolates } \\
\text { from pharyngeal swab specimens }\end{array}$} & \multicolumn{2}{|c|}{$\begin{array}{l}\mathrm{MIC}(\mu \mathrm{g} / \mathrm{ml}) \text { required to inhibit } \\
\text { following }(\%) \text { of } 84 \text { isolates } \\
\text { from urine specimens }\end{array}$} & \multicolumn{2}{|c|}{$\begin{array}{c}\mathrm{MIC}(\mu \mathrm{g} / \mathrm{ml}) \text { required to inhibit } \\
\text { following }(\%) \text { of } 185 \text { isolates } \\
\text { from pus specimens }\end{array}$} \\
\hline & & & ${\operatorname{MIC} 50^{\mathbf{a}}}$ & $\mathrm{MIC} 0^{\mathbf{a}}$ & $\mathrm{MIC} 0^{\mathrm{a}}$ & $\mathrm{MIC}^{\mathrm{a}}$ & MIC $50^{\mathrm{a}}$ & $\mathrm{MIC}^{2} 0^{\mathrm{a}}$ \\
\hline Arbekacin & $0.01 \sim 25$ & 0.78 & 0.78 & 1.56 & 0.78 & 1.56 & 0.78 & 1.56 \\
\hline Gentamicin & $0.05 \sim \geq 800$ & 50 & 50 & 200 & 50 & 200 & 50 & 200 \\
\hline Amikacin & $12.5 \sim \geq 800$ & $\geq 800$ & $\geq 800$ & $\geq 800$ & 25 & 100 & 25 & 100 \\
\hline Fosfomycin & $0.39 \sim \geq 800$ & $\geq 800$ & $\geq 800$ & $\geq 800$ & $\geq 800$ & $\geq 800$ & 25 & 100 \\
\hline Chloramphenicol & $1.56 \sim 100$ & 12.5 & 12.5 & 100 & 25 & 100 & 12.5 & 100 \\
\hline Minocycline & $0.02 \sim 50$ & 12.5 & 12.5 & 25 & 12.5 & 25 & 25 & 50 \\
\hline Imipenem & $0.01 \sim \geq 200$ & 25 & 25 & 50 & 25 & 50 & 25 & 50 \\
\hline Methicillin & $12.5 \sim \geq 800$ & $\geq 800$ & $\geq 800$ & $\geq 800$ & $\geq 800$ & $\geq 800$ & $\geq 800$ & $\geq 800$ \\
\hline Vancomycin & $\leq 0.2 \sim 3.13$ & 0.78 & 0.78 & 1.56 & 0.78 & 3.13 & 0.78 & 1.56 \\
\hline Ofloxacin & $\leq 0.01 \sim \geq 100$ & 6.25 & 6.25 & $\geq 100$ & $\geq 100$ & $\geq 100$ & 6.25 & $\geq 100$ \\
\hline \multirow[t]{2}{*}{ Drug } & \multicolumn{2}{|c|}{$\begin{array}{l}\mathrm{MIC}(\mu \mathrm{g} / \mathrm{ml}) \text { required to inhibit } \\
\text { following }(\%) \text { of } 90 \text { isolates } \\
\text { from nose specimens }\end{array}$} & \multicolumn{2}{|c|}{$\begin{array}{l}\mathrm{MIC}(\mu \mathrm{g} / \mathrm{ml}) \text { required to inhibit } \\
\text { following }(\%) \text { of } 25 \text { isolates } \\
\text { from sputum specimens }\end{array}$} & \multicolumn{2}{|c|}{$\begin{array}{l}\mathrm{MIC}(\mu \mathrm{g} / \mathrm{ml}) \text { required to inhibit } \\
\text { following }(\%) \text { of } 30 \text { isolates } \\
\text { from miscellaneous specimens }\end{array}$} & & \\
\hline & MIC50 $0^{a}$ & $\operatorname{MIC} 90^{a}$ & $\operatorname{MIC} 50^{\mathrm{a}}$ & $\mathrm{MIC}^{\mathrm{a}}$ & $\operatorname{MIC} 50^{\mathrm{a}}$ & $\mathrm{MIC}^{\mathrm{a}}$ & & \\
\hline Arbekacin & 0.78 & 1.56 & 0.78 & 1.56 & 0.78 & 1.56 & & \\
\hline Gentamicin & 25 & 100 & 50 & 200 & 50 & 200 & & \\
\hline Amikacin & 25 & 100 & 25 & 25 & 12.5 & 25 & & \\
\hline Fosfomycin & $\geq 800$ & $\geq 800$ & 400 & $\geq 800$ & $\geq 800$ & $\geq 800$ & & \\
\hline Chloramphenicol & 12.5 & 100 & 12.5 & 50 & 25 & 100 & & \\
\hline Minocycline & 25 & 50 & 12.5 & 25 & 12.5 & 25 & & \\
\hline Imipenem & 25 & 50 & 25 & 50 & 25 & 50 & & \\
\hline Methicillin & $\geq 800$ & $\geq 800$ & $\geq 800$ & $\geq 800$ & $\geq 800$ & $\geq 800$ & & \\
\hline Vancomycin & 0.78 & 1.56 & 0.78 & 1.56 & 0.78 & 1.56 & & \\
\hline Ofloxacin & 6.25 & $\geq 100$ & 6.25 & $\geq 100$ & 6.25 & $\geq 100$ & & \\
\hline
\end{tabular}

a The concentrations of the drugs required to inhibit the growth of 50\% (MIC50) and 90\% (MIC90) of the total number of MRSA strains tested. 
suggested the involvement of, at least, more than one aminoglycoside modifying enzymes with the $\mathrm{ABK}$ resistance. Genetic analysis of the ABK resistance for the two strains are currently in progress. None of the MRSA strains examined was resistant to VCM. Along with DMPPC, FOM exhibited the lowest degree of activity among the drugs examined except for the strains from pus materials. This was also the case for AMK, that is, the drug exhibited the lowest activity on the strains from pus when compared with the strains from the other sources. We have been unable to clarify why only the strains from pus exhibited significantly higher suscetibility to the two drugs.

Our results have clearly shown that $\mathrm{ABK}$ is one of the few potent chemotherapeutic agents against MRSA, that is, although two $(0.4 \%)$ ABK-resistant strains have been found among 496 strains, its modal MIC of the drug was $0.78 \mu \mathrm{g} / \mathrm{ml}$. As expectedly, another effective agent among the drugs tested was VCM and its modal MIC was also $0.78 \mu \mathrm{g} / \mathrm{ml}$. For all of the other eight kinds of chemotherapeutic agents, their modal MICs ranged from $12.5 \mu \mathrm{g} / \mathrm{ml}$ to more than $800 \mu \mathrm{g} / \mathrm{ml}$. ABK would be an advantageous drug because, in contrast to VCM which is active only on Gram-positive bacteria, antimicrobial spectrum of ABK is not confined to only Staphylococcus aureus strains but it can inhibit growth of diverse species of both Gram-positive and Gram-negative bacteria including Pseudomonas aeruginosa strains ${ }^{12.13)}$.

A criticism to our results would be that, as the strains examined had been isolated from a limited environment, that is, only in our hospital, hence the results may not represent the susceptibility of MRSA strains now widely distributed in Japan. However, the number of resistant pattern of our strains for the ten agents tested counted twelve, but none of them was predominant (data not shown). We have also classified approximately one hundred isolates among the strains tested into the eleven types by Pulsed Field Gel Electrophoresis for the genomic DNAs digested with SmaI and in this case, none of the type was significantly prevalent nor associated with a particular drug resistant pattern (data not shown). We since did not consider that the strains used represented only a few number of clones of the MRSA strains that were distributed in our hospital during the period we isolated them.

\section{Acknowledgement}

We express our deep thanks to Meiji Seika Kaisha,
Ltd., Tokyo, Japan, for supply of standard powder of Arbekacin and for financial support of this study.

\section{References}

1) BoycE, J. M.: Methicillin-resistant Staphylococcus aureus. Detection, epidemiology, and control measures. Infect. Dis. Clin. North Am. 4: 901 913, 1989

2) Brumfitt, W. \& J. Hamilton-Miller: Methicillinresistant Staphylococcus aureus. N. Engl. J. Med., 320: $1188 \sim 1195,1989$

3) Kawakami, Y; Y. Okimura, Y. Morizumi, T. KATSUYAMA \& M. KANAI: In vitro activity of cefotiam alone and in combination with imipenem against recent clinical isolates of methicillin- and cephemresistant Staphylococcus aureus. Med. Sci. Res. 18 $63 \sim 65,1990$

4) KawaKami, Y.; Y. OKimura, M. Itoh \& M. KanaI: A change of infecting microorganisms from in- and out-patients at Shinshu University Hospital, Japan. Antibiot. Chemother. 4: 96 104, 1988

5) Alvarez, S.; M. Jones \& S. L. BerK: In vitro activity of fosfomycin, alone and in combination, against methicillin-resistant Staphylococcus aureus. Antimicrob. Agents Chemother. 28: 689 690, 1985

6) Thompson, R. L.; I. Cabezudo \& R. P. Wenxel: Epidemiology of nosocomial infections caused by. methicillin-resistant Staphylococcus aureus. Ann. Intern. Med. 97: 309 317, 1982.

7) Fillastre, J. P.; A. Leroy, G. Humbert, B. Moulin, P. Bernadet \& S. Josse: Pharmacokinetics of habekacin in patients with renal insufficiency. Antimicrob. Agents Chemother. 31: 575 577, 1987

8) PRICE, K. E.: The potential discovery and development of improved aminoglycosides 1986. Am. J. Med. 80 (suppl 6B): 182 188, 1986.

9) Reynaud, A. E.; B. C. Foresto, M. Derriennic \& A. L. Courtieu: Activite comparee de l'habekacine et de quatre autres aminosides a l'egard des bacilles gram negatif evolution de la resistance. Pathol. Biol. 36: $435 \sim 438,1988$.

10) LAU, W. Y.; C. H. THEH-CHAN \& K. F. LAU: In vitro and in vivo fosfomycin in methicillin-resistant Staphylococcus aureus septicemia. J. Hyg. Camb., 96: $419 \sim 423,1986$.

11) ThORnsberry, C. \& L. K. MCDOUgal: Successful use of broth microdilution in susceptibility tests for methicillin-resistant (heteroresistant) Staphylococci. J. Clin. Microbiol. 18: 1084 1091, 1983.

12) Kondo, S.; K. Iinuma, H. Yamamoto, K. Maeda \& $\mathrm{H}$. UMeZawa: Synthesis of $1-N$-[(S)-4-amino-2hydroxybutyryl]-kanamycin $\mathrm{B}$ and $-3^{\prime}, 4^{\prime}$-dideoxykanamycin $B$ active against kanamycin-resistant bacteria. J. Antibiotics 26: 412 415, 1973

13) Umezawa, H.; S. Kondo \& I. Kitasato: Development of new semi-synthetic aminoglycoside antibiotics. Drugs Exp. Clin. Res. 10: 631 636, 1984. 